\title{
HEMATOMA INTRAPROTUBERANCIAL
}

\author{
Rolando A. 'Tenuto * \\ Oswaldo Ricciardi CRUZ**
}

As hemorragias primárias maciças da protuberância apresentam aspecto clínico e anatomopatológico definidos tendo, desde longa data, despertaco a atenção de neurologistas e anatomo-patologistas. A incidência dessa entidade, dentro dos acidentes vasculares cerebrais, oscila entre 2 a 10 por cento (Manchi e Sanginario 4, Epstein ', Környey ${ }^{3}$, Fang e Foley ${ }^{2}$ ). O quadro clinico, de instalação aguda, é caracterizado por coma profundo, hiptertonia em extensão do tipo decerebrado, miose bilateral; a evolução é fatal na maioria dos casos. Em alguns casos há comprometimento de nervos cranianos ${ }^{5}$. Pode ocorrer síndrome de hipertensão intracraniana revelável pelo exame oftalmoscópico e pela punção raquidiana. Em 65 por cento dos casos de Steegmann ${ }^{5}$ foram observadas alterações respiratórias, desde ritmos anormais até apnéia. A etiopatogenia está sempre relacionada a moléstias cardiovasculares hipertensivas; em alguns casos têm sido assinaladas moléstias associadas tais como diabetes, lúes e toxemia gravídica.

Nos propusemos ao registro dêste caso pelas peculiaridades do quadro neurológico observado, por ter o hematoma determinado bloqueio da circulação do líqüido cefalorraquidiano e pelo bom resultado obtido com a derivação do trânsito ventrículo-subaracnoídeo.

OBSERVAÇĀo - J. S., 33 anos, branca, sexo feminino, internada na Clinica Neurológica em março de 1958 (Reg. geral 466.832). Início súbito da moléstia há três anos com cefaléia, náuseas e vômitos. Esses sintomas permaneceram com intensidade variável até há dois anos, quando ocorreu perda da acuidade visual em ambos os olhos, de caráter progressivo. Há dois meses surgiu, de modo brusco, adormecimento na hemiface direita, associada a sensaçōes parestésicas principalmente ao redor do globo ocular. Antecedentes - Processo pleurítico, ocorrido na infância, com recuperação integral. Exame clínico-neurológico - Paciente normotensa, afebril, normal o exame clínico geral e especial; hipoestesia tactil, térmica e dolorosa na face, no território do $\mathrm{V}$ nervo craniano à direita; diminuição da sensibilidade corneana e do reflexo córneo-palpebral; paresia facial periférica à direita

Trabalho da Clínica Neurológica da Fac. Med. da Univ. de São Paulo (Prof. Adherbal Tolosa). * Chefe do Servico de Neurocirurgia. ** Assistente extranumerário. 
com ausência do reflexo de Mc Carthy; hipoacusia à direita. Exames complementare: - Audiograma: moderada hipoacusia para os sons graves particularmente à direita. Oftalmoscopia: edema de papila bilateral de duas dioptrias, com áreas de hemorragias retinianas peri-papilares e edema de retina. Os exames laboratoriais de rotina, inclusive a reação para cisticercose no sangue foram negativos. Eletrencefalograma: moderada assimetria entre a atividade dos hemisférios cerebrais, sem elementos que permitissem localização. Exame radiológico simples do crânio: erosão das apófises clinóides posteriores e do segmento posterior do assoalho selar; aspecto radiológico normal dos meatos auditivo se das pirâmides temporais. Foram feitas, entāo, perfurações occiptais e punçio ventricular: o liqüido obtido era límpido e incolor, com pressão inicial de $22 \mathrm{~cm}$ de água, sendo as reações e dosagens normais.. Iodoventriculografia: dilatạão do III ventrículo e bloqueio do trânsito an nivel do IV ventriculo, o qual se apresenta dilatado nas incidencias lateral e ântero-posterior, sem apresentar desvios em relação ao plano médio-sagital; imagem iodoventriculográfica compativel com o diagnóstico de processo expansivo ao nivel da porção média do ventriculo rombencefálico (fig. 1).
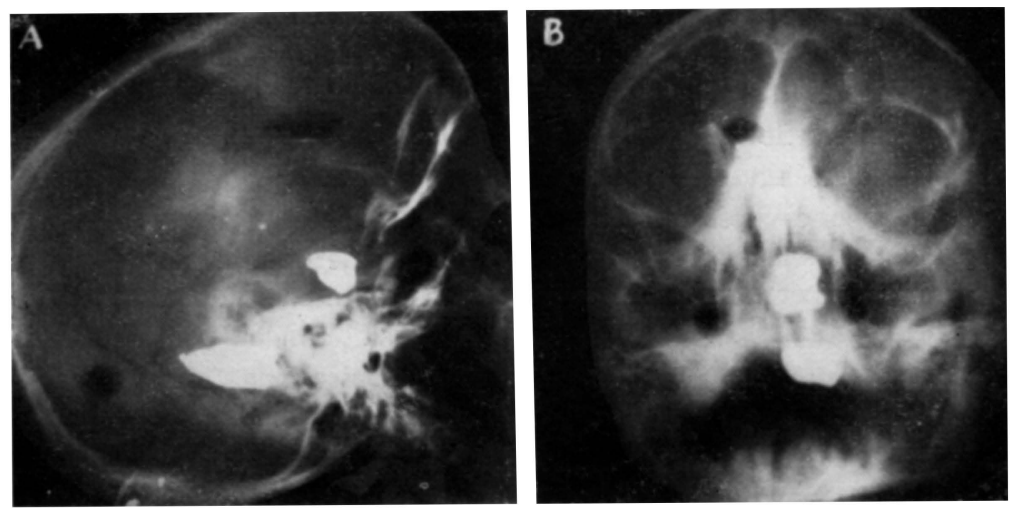

Fig. 1 - Iodoventriculografia: dilatacio do III ventriculo e bloqueio do trânsito ao nivel do IV ventriculo, o qual se encontra também dilatado (A); nuio há desvios em relacrio ao plano médio-sagital $(B)$.

Intervençio cirurgica - Craniectomia de fossa posteriur, tipo bimastoidéia nos moldes clássicos. A exploracão do assoalho do IV ventriculo mostrou, ao nível de sua porcão intermédia, um abaulamento de consistencia dura que bloqueava essa cavidade. Ao nivel das estrias medulares afloravam pequenos coágulos sanguíneos. Feita a incisão do abaulamento, foi colhido material das paredes mediana e laterais para o exame anátomo-patológico. Foi feita, a seguis, uma derjvacão ventrículo-subaracnóidea usando a cisterna de ângulo ponto-cerebelar dada a impossibiliclade de realizar a operação de Torkildsen nos moldes clássicos.

Exame histológicos coágulos sangüineos em organização; não foi encontrado qualquer indicio de processo neoplásico.

No pós-operatório manteve-se a sindrome de hipertensão intracraniana, agravando-se o estado geral progressivamente. Com intuito de verificar a possível existênria de malformação vascular no território da artéria basilar foi feita angiografia cerebral via artéria vertebrl, com resulto normal. A persistencia da sindrome de hipertensão intracraniana indicou que se tornava necessária nova modalidade de 
derivação do trânsito liquórico, optando-se pela abertura da lãmina terminalis. Após essa segunda intervenção regrediram os sinais de hipertensão intracraniana e houve acentuada melhora do estado geral. Evoluçũo - Três meses após a intervenção a paciente apresentava quadro neurológico idêntico ao de sua admissão, notando-se apenas melhora da acuidade visual e do estado físico geral.

\section{COMENTÁRIOS}

Os sinais neurológicos sindrome de hipertensão intracraniana e lesão parcial dos V, VII, e VIII nervos cranianos à direita - levaram à hipótese inicial de processo expansivo situado no ângulo ponto-cerebelar; entretanto, o quadro iodoventriculográfico, evidenciando bloqueio ao nivel da porção média do IV ventrículo sem desvios laterais, afastou por completo esta hipótese. Sòmente o ato cirúrgico possibilitou o diagnóstico etiológico (hematoma intraprotuberancial). Não havia qualquer elemento clinico, dos que usualmente acompanham os processos vasculares pontinos maciços, que nos levasse a essa hipótese. A permanência do bloqueio do trânsito ventrículo-subaracnóideo após a exploração da fossa posterior nos parece ser devido à ineficácia da derivação praticada na primeira intervenção, utilizando a cisterna de ângulo ponto-cerebelar, pois foi tècnicamente impossivel, por óbvias razões, a feitura da operação clássica de Torkildsen. Com a abertura da lâmina terminalis em intervenção subsequente, foi resolvido plenamente o problema de hipertensão intracraniana. A melhora do quadro clínico no pós-operatório tardio demonstra a benignidade do processo. Não encontramos, em nosso caso, antecedentes que nos levassem a um diagnóstico etiopatogênico.

\section{RESUMO}

Os autores apresentam um caso de hematoma intraprotuberancial com bloqueio do trânsito do líqüido cefalorraquidiano na porção média do quarto ventrículo. Os sinais neurológicos e a evoluçāo clínica do caso afastavamse daqueles observados nos processos hemorrágicos maciços ao nivel da ponte. O tratamento cirúrgico, uma vez verificada a impossibilidade da excisão, consistiu em derivação do trânsito liquórico por meio da abertura da lâmina terminalis. O caso evolveu favoràvelmente.

\section{SUMMARY}

\section{Primary pontile haematoma}

A case of pontile haematoma blocking the flow of the spinal fuid in the pars intermedia of the fourth ventricle is reported. Neurological signs and clinical evolution of this case were dissimilar of those observed in massive pontile hemorrhage. By the impossibility of the excision, was made the derivation of the spinal fluid flow by opening the lamina terminalis. 


\section{BIBLIOGRAFIA}

1. EPSTEIN, A. W. - Primary massive pontile hemorrhage. O clinical pathological study. J. Neuropatol. a. Exp. Neurol., 10:426, 1951. 2. FANG, H. C. H.; FOLEY, J. M. - Hipertensive hemorrhages of the pons and cerebelum. Arch. Neurol. a. Psychiat., $72: 638,1954,3$. KORNEYEY, S. — Rapidly fatal pontile hemorrhage: clinical and anatomic report. Arch. Neurol. a. Psychiat., 41:739, 1939. 4. MANCHI, E.; SANGINARIO, M. - Ipertonia estensoria simil-decerebrata da emorragia nel terzo inferiore del ponte. Riv. Patol. Nerv. e Ment., 78:529, 1957. 5. STEEGMANN, A. T. - Primary pontile hemorrhage whith particular reference to respiratory failure. J. Nerv, a. Ment. Dis., 114:35, 1951.

Clínica Neurológica. Hospital das Clínicas da Fac. Med. da Univ. de São Paulo - Caixa Postal 3461 - São Paulo, Brasil. 